\title{
How Not to Be Overwhelmed by Obvious Advice
}

COMMUNICATION CORNER No. 20

\section{by Philip Yaffe}

\section{Editor's Introduction}

Each "Communication Corner" essay is self-contained; however, they build on each other. For best results, before reading this essay and doing the exercise, go to the first essay "How an Ugly Duckling Became a Swan," then read each succeeding essay.

With unprecedented access to information, the internet can be a source of useful material. However many times, so-called experts share specious advice. In this article, Phil Yaffe addresses a widely discussed topic, clear writing, and dives deeper to fix the flaws found in regurgitated writing advice. 


\title{
How Not to Be Overwhelmed by Obvious Advice
}

\author{
COMMUNICATION CORNER No. 20
}

\begin{abstract}
by Philip Yaffe
In the previous installment, we took a close-up look at the functional definition of "concise," i.e. as long as necessary, as short as possible, and saw how useful it is in preparing an expository (non-fiction) text that most people will probably want to read. As you will recall, there are two other functional definitions needed to render an expository text effective: "clear," and "dense." We are going to take a second look at these now (see Communication Corner No. 2 "The Three Acid Tests of Persuasive Writing").

Remember: What induces most people most of the time to read an expository text is it quickly tells them what benefit they can expect to gain from doing so. I will now do the same thing with this text.

I solemnly promise that after reading this more profound review of what you have already seen, you will find writing an effective expository text and preparing an effective expository speech considerably easier. This review is a modified version of an essay I wrote a few years ago in response to some nonsense I found on the internet.
\end{abstract}

\section{Fixing the Flaws in the Ten "Principles" of Clear Writing}

A list of "Ten Principles of Clear Writing" widely circulating on the internet offers much useful advice; however, these so-called "principles" are only tips and techniques. In reality, they are built on our three true principles of clarity, conciseness, and density described in Communication Corner No. 2. By keeping these three true principles firmly in mind, you can apply the 10 tips and techniques that grow from them with greater ease and impact.

You should already know each principle by heart, but they can never be repeated too often, so here they are again.

- Clarity

For a text to be clear, the writer must identify and emphasize what is of primary importance (key ideas), de-emphasize what is of secondary importance (information supporting key ideas), and eliminate what is of no importance (irrelevant information). 


\section{- Conciseness}

For a text to be concise, the writer must cover all the key ideas and supporting information identified under "clarity," and do so in a minimum of words.

\section{- Density}

For a text to be dense, the writer must use specific information to add substance, then clearly show the logical link between related information to avoid misinterpretation.

\section{Ten Tips and Techniques}

\section{Keep sentences short}

This is usually interpreted to mean an average sentence length of 15-18 words. Not because readers can't handle longer sentences; however, when length rises above this average, sentences are likely to be poorly constructed, thereby damaging clarity.

But remember, 15-18 words is an average. Don't shun longer sentences. A wellconstructed long sentence is often clearer than two or more shorter ones. Why? Because the longer sentence better shows the logical linkage among the various elements, which would be lost by splitting it apart.

\section{Prefer the simple to the complex}

If the precise word is long, don't hesitate to use it, because not using it would damage clarity. On the other hand, if a shorter word would do just as well, prefer it. Examples: "dog" rather than "canine," "change" rather than "modification," "entrance" rather than "ingress."

\section{Prefer the familiar word}

This is just a variation of point no. 2. If you have a choice between two words, use the one that most people are likely to recognize and use themselves. Examples: "insult" rather than "imprecate," "daily" rather than "quotidian."

\section{Avoid unnecessary words}

In other words, be concise. 


\section{Use active verbs}

In an individual sentence, whether you use an active or a passive verb is of little consequence. However, over an entire text, it becomes very important. Active verbs tend to enhance clarity; conversely, too many passive verbs tend to damage it.

\section{Write the way you speak}

This is a very useful technique, but don't take it literally. When we speak, we generally use simpler vocabulary and sentence structures than when we write. Writing the way you speak is a good way to produce the first draft. However, when we speak, our sentence structures are often confused and our vocabulary imprecise. These faults must be rigorously corrected in the second, third or later drafts.

\section{Use terms your reader can picture}

In other words, be dense. Use specifics; avoid weasel words. When making a general statement, be certain to support it with concrete data.

\section{Tie in with your reader's experience}

We are again talking about density, i.e. using precise information. Be certain that the terminology you chose is compatible with your reader's experience. If you need to use a word not likely to be familiar to your readers, define it the first time it appears. If it is key, define it again later on in the text. Also, be wary of words that look familiar but have a very different meaning in the context of your subject.

Example: "Insult" is medical jargon for an injury or trauma. However, talking about an "insult" to the heart without first explaining this unconventional meaning of the word is likely to leave your readers scratching their heads.

\section{Make full use of variety}

This suggestion is almost superfluous. If you conscientiously apply the three writing principles of clarity, conciseness, and density, you will almost automatically introduce a variety of sentence lengths and structure into your text. 
Avoid introducing too much variety of vocabulary. Constantly the changing terminology for the sake of variety damages clarity. If several words mean essentially the same thing, pick one or two of them and shun the others. Introduce equivalent terms in such a way that the reader clearly understands that they mean the same thing. Here's an example.

\section{Confusing}

Manned space travel to Mars is once again being considered. The Red Planet has fascinated mankind for centuries. The "God of War" is the fourth planet from the Sun our own Earth is the third-and it is our closest celestial neighbor except for the moon.

\section{Clear}

Manned space travel to Mars is once again being considered. Popularly known as the "Red Planet," Mars has fascinated mankind for centuries. Being the fourth planet from the Sun (Earth is the third), it is our closest celestial neighbor except for the moon.

\section{Write to express, not to impress}

The purpose of expository writing is to instruct or inform, not to show off your literary prowess. The fact is, the better you write, the fewer people are likely to notice. And this is how it should be. The reader's full attention should be on what you are saying, not how you are saying it.

So there you have it. Ten so-called principles for writing an effective text or preparing a good speech reduced to only three real principles (clear, concise, dense).

I said at the outset that reading this essay would make writing an effective text and preparing an effective speech considerably easier. I think I have kept my promise. I hope you agree.

\section{About the Author}

Philip Yaffe was born in Boston, Massachusetts, in 1942 and grew up in Los Angeles, where he graduated from the University of California with a degree in mathematics and physics. In his senior year, he was also editor-in-chief of the Daily Bruin, UCLA's daily student newspaper. He has more than 40 years of experience in journalism and international marketing communication. At various points in his career, he has been a teacher of journalism, a reporter/feature writer with The Wall Street Journal, an account executive with a major international press relations agency, European marketing communication director with two major international companies, and a founding partner of a specialized marketing communication agency in Brussels, Belgium, where he has lived since 1974 . He is the author of more than 30 books, which can be found easily in Amazon Kindle. 
DOI: $10.1145 / 3375552$ 